TITLE:

\title{
Improving withstand voltage by roughening the surface of an insulating spacer used in vacuum
}

\author{
$\operatorname{AUTHOR}(S):$ \\ Yamamoto, O; Takuma, T; Fukuda, M; Nagata, S; \\ Sonoda, $\mathrm{T}$
}

\section{CITATION:}

Yamamoto, O ...[et al]. Improving withstand voltage by roughening the surface of an insulating spacer used in vacuum. IEEE TRANSACTIONS ON DIELECTRICS AND ELECTRICAL INSULATION 2003, 10(4): 550-556

ISSUE DATE:

2003-08

URL:

http://hdl.handle.net/2433/39980

\section{RIGHT:}

(c)2003 IEEE. Personal use of this material is permitted. However, permission to reprint/republish this material for advertising or promotional purposes or for creating new collective works for resale or redistribution to servers or lists, or to reuse any copyrighted component of this work in other works must be obtained from the IEEE. 


\title{
Improving Withstand Voltage by Roughening the Surface of an Insulating Spacer Used in Vacuum
}

\author{
O. Yamamoto, T. Takuma, M. Fukuda, S. Nagata \\ Department of Electrical Engineering \\ Kyoto University, Kyoto, Japan \\ and T. Sonoda \\ The Kansai Electric Power Co. Inc., Osaka, Japan
}

\begin{abstract}
This paper describes a simple and reliable method of improving the surface insulation strength of a spacer used in vacuum. The method is to roughen the spacer surface to an average roughness $R_{a}$ higher than 1 or $2 \mu \mathrm{m}$. The material of the spacer examined is $\mathrm{SiO}_{2}, \mathrm{PMMA}$, PTFE or $\mathrm{Al}_{2} \mathrm{O}_{3}$ and their shape is a right cylinder with $10 \mathrm{~mm}$ in height and $54 \mathrm{~mm}$ in diameter. The spacer is subjected to a ramped dc voltage and its surface charging is observed by using an electrostatic probe embedded in the cathode. It has been found that $\boldsymbol{R}_{a}$ decisively affects the charging, which decreases as $R_{a}$ increases. Increasing $R_{a}$ larger than about $2 \mu \mathrm{m}$ suppresses the charging until a higher applied voltage is reached, thus improving the insulation property.
\end{abstract}

Index Terms - Charging, flashover voltage, insulating spacer, roughness, vacuum.

\section{INTRODUCTION}

$\mathrm{S}^{\mathrm{U}}$ URFACE discharge along solid insulators (spacers) is an important factor to be considered in designing high voltage vacuum devices. In vacuum, the charging along the surface of an insulating spacer precedes the flashover. The charging takes place through a process in which electrons released from a triple junction, where the cathode, insulator and vacuum meet, propagate toward the anode causing a secondary emission electron avalanche (SEEA) along the insulator surface [1]. Thus, it is believed that the secondary electron emission characteristics have a pronounced effect on the charging and eventually on the withstand voltage.

According to a report by Kawai et al. [2], surface polishing leads to an increase in the secondary emission yield. Bommakanti et al. [3] have pointed out that surface polishing results in withstand voltage reduction. The authors have reported that increasing surface roughness delays considerably the surface charging due to pulsed voltage excitation [4].

This study aims at clarifying quantitatively the relationship between surface roughness and insulation strength in order to obtain useful data for designing an efficient insu-

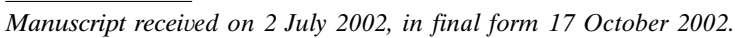

lating spacer in vacuum. We have examined flashover and charging characteristics of a cylindrical insulator having various degrees of surface roughness under ramped $\mathrm{dc}$ voltage excitation. Charging is observed using an electrostatic probe embedded in the cathode. Also, we have conducted the simulation of electron trajectories to discuss the influence of roughness on charging.

Based on these experimental and simulation results, we clarify the influence of surface roughness on insulation strength and charging of insulating spacers in vacuum.

\section{EXPERIMENTAL}

The insulating spacers studied are made of fused quartz $\left(\mathrm{SiO}_{2}\right)$, Polymethyl methacrylate (PMMA), Alumina $\left(\mathrm{Al}_{2} \mathrm{O}_{3} .92 \%\right.$ purity) or Teflon ${ }^{\circledR}$ (PTFE), in the shape of a cylinder with $10 \mathrm{~mm}$ height and $54 \mathrm{~mm}$ diameter. These specimens were subjected to a ramped dc voltage at a rising rate of $0.25-2 \mathrm{kV} / \mathrm{s}$.

The $\mathrm{SiO}_{2}$ insulator has an average roughness $R_{a}$ of 0.03-3.07 $\mu \mathrm{m}$ (5 classes). The specimen with $0.03 \mu \mathrm{m}$ roughness was polished to a mirror-like smoothness by using buff, and the others were processed by using an emery wheel having various grain sizes.

The PMMA insulator has $R_{a}=0.13-27.1 \mu \mathrm{m}$ (8 classes). The specimens with roughness of $R_{a}=0.13,0.19$ 
Table 1. Properties of the insulating materials examined.

\begin{tabular}{lcccc}
\hline & $R_{a}(\mu \mathrm{m})$ & $\delta_{\max }$ & $A_{\delta \max }(\mathrm{eV})$ & $\epsilon_{r}$ \\
\hline $\mathrm{SiO}_{2}$ & $0.03-3.07$ & $2.9^{[5]}$ & 400 & 3.6 \\
$\mathrm{PMMA}$ & $0.13-27.1$ & $2.3^{[6]}$ & 240 & $3.0-4.0$ \\
$\mathrm{PTFE}$ & $0.25-37.8$ & $2.1^{[6]}$ & 400 & 2 \\
$\mathrm{Al}_{2} \mathrm{O}_{3}$ & $0.13-11.5$ & $5-7^{[2]}$ & $0.8-2 \mathrm{k}$ & 9 \\
\hline
\end{tabular}

and $0.22 \mu \mathrm{m}$ were polished to mirror-like smoothness using a polymer-polishing compound. The specimens with $R_{a}=0.71,1.70$ and $3.05 \mu \mathrm{m}$ were roughened by using emery papers having different grain sizes. The other PMMA specimens, $R_{a}=6.01$ and $27.1 \mu \mathrm{m}$, were mechanically processed by using a lathe, and therefore, they had a spiral scare on the surface.

The PTFE spacer has $R_{a}=0.25-37.8 \mu \mathrm{m}$ (7 classes). The specimen with $R_{a}=0.25 \mu \mathrm{m}$ was polished using a polymer-polishing compound. The specimens with $R_{a}=$ $0.58,1.30$ and $2.0 \mu \mathrm{m}$ were roughened by using emery papers. The other PTFE specimens, $R_{a}=4.66,8.06$ and $37.8 \mu \mathrm{m}$, were processed by using a lathe.

The $\mathrm{Al}_{2} \mathrm{O}_{3}$ insulator has $R_{a}=0.13-11.5 \mu \mathrm{m}$ (7 classes). Four of them $\left(R_{a}=0.13-0.37 \mu \mathrm{m}\right)$ were polished with diamond powder, and the other specimens, except for one $\left(R_{a}=1.43 \mu \mathrm{m}\right)$, were processed using a lathe with a diamond bite. The $1.43 \mu \mathrm{m}$ specimen was made by sintering without mechanical processing (i.e. original surface).

In order to remove various contaminants that would remain on the insulator surface during the roughening or polishing process, each insulator was cleaned by using an ultrasonic vibrator, then rinsed with distilled water and dried before installing in a test vessel. Table 1 summarizes the above-mentioned roughness $R_{a}$ together with other properties such as the maximum secondary electron yield $\delta_{\max }$, its impinging energy $A_{\delta \max }$ and the relative permittivity $\epsilon_{r}$.

The experiment was performed in a test vessel evacuated to $1 \times 10^{-3} \mathrm{~Pa}$ by using a turbo molecular pump connected to a rotary pump. The probe is a ring shaped part isolated from the grounded planar cathode and is located coaxially with the cylindrical specimen as shown in Figure 1 . We use this probe arrangement to observe the charging

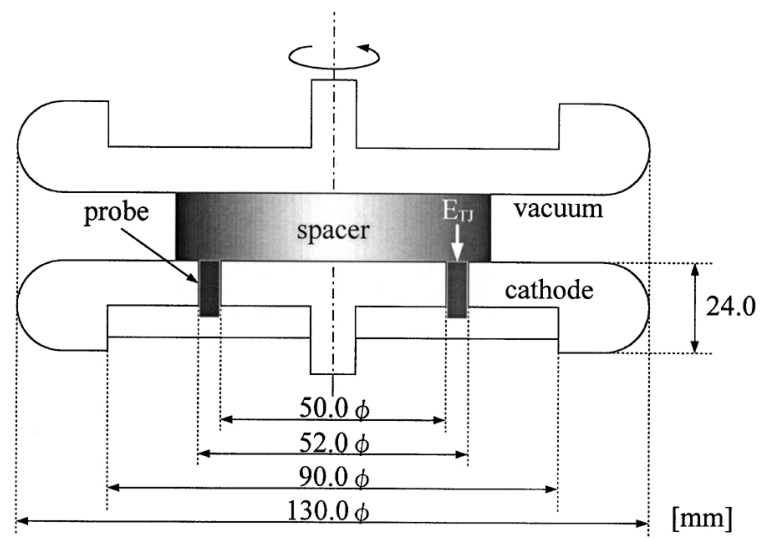

Figure 1. Arrangement of an insulator and a probe. process of the insulating spacers without disturbing the geometrical electric field distribution in the gap. Also, as the probe surface is entirely covered by the insulating spacer, this arrangement guarantees the electrostatic charge measurement, where no charge flows into the probe through the vacuum. The probe is grounded through a capacitor, and its signal is converted into electric field strength $E_{T J}$, which is the sum of the geometrical field component $E_{g}$ and the surface charge component $E_{s}$. $E_{T J}$ $=E_{g}+E_{s}$. The geometrical field $E_{g}$ equals to $V_{a p} / d$, where $V_{a p}$ is the applied voltage, and $d$ the electrode separation. Further details of the probe measurement have been described in a previous paper [7].

In order to avoid shot-to-shot variations of the charge measurement due to remnant charge on the insulator surface, it was neutralized each time before conducting the successive measurement. The remnant charge was effectively neutralized by a silent discharge which took place when a small amount of air was introduced into the vacuum vessel. When flashover tests were performed to investigate the withstand ability of an insulator, the above procedure was not adopted until ten flashover voltages were measured. This is mainly to save experimental time. When the neutralization procedure was adopted after each of the successive flashovers, we obtained a flashover voltage a little lower (ca. 10\%) than that without the neutralization.

\section{FLASHOVER CHARACTERISTICS}

\subsection{FLASHOVER RECORDS}

Each specimen is subjected to 10 ramped voltages to measure the flashover voltage. Figure 2 shows the records of flashover voltage in series of voltage application for $\mathrm{SiO}_{2}$ and PMMA specimens. It can be seen that the flashover voltage is higher for a larger roughness for both

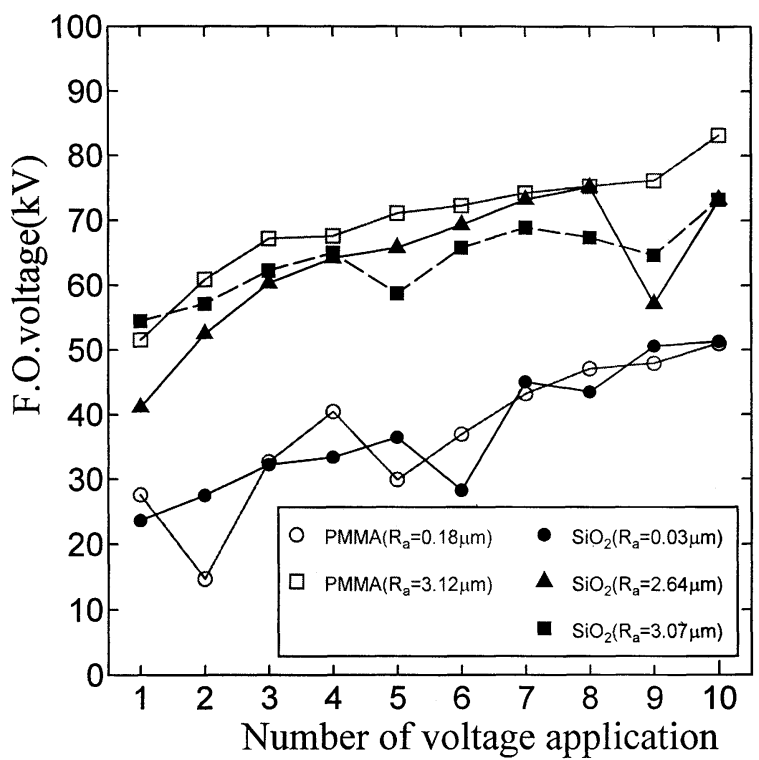

Figure 2. Flashover records of $\mathrm{SiO}_{2}$ and PMMA insulators. 


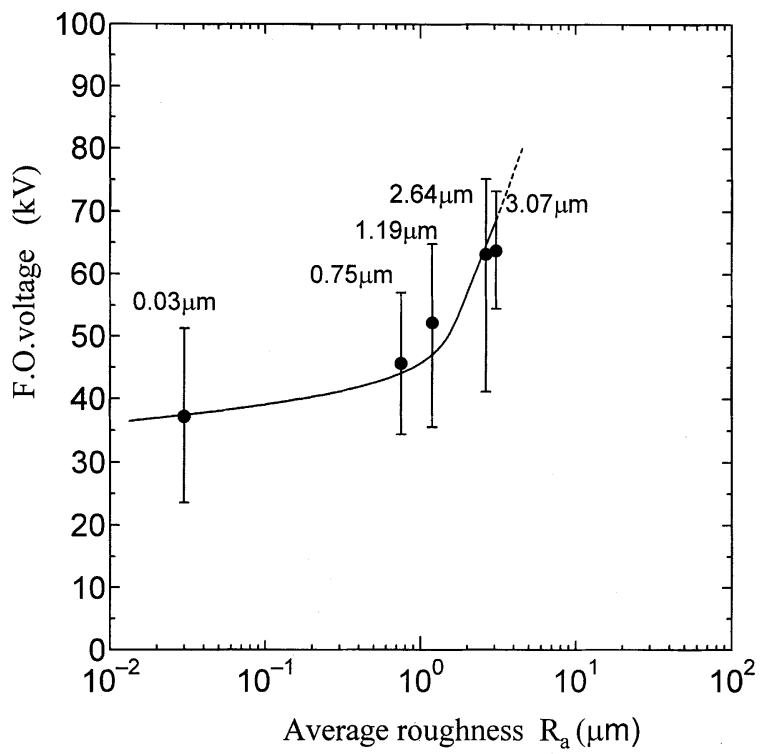

(a)

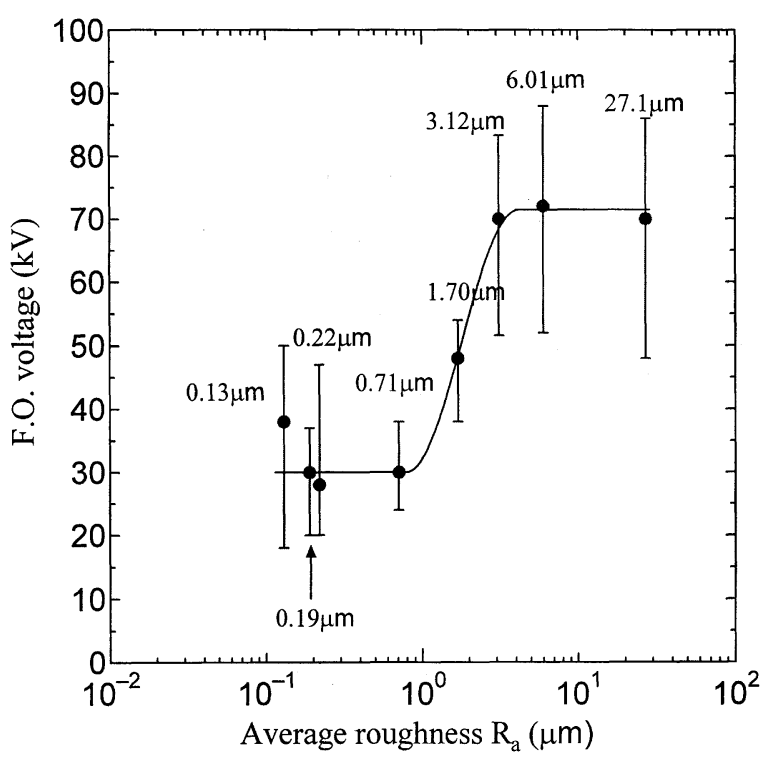

(b)

Figure 3. Flashover characteristics of $\mathrm{SiO}_{2}$ and PMMA. a, $\mathrm{SiO}_{2} ; \mathrm{b}$, PMMA.

materials. Note that the first flashover voltage increases also with the roughness. The flashover records for $\mathrm{SiO}_{2}$ and PMMA are very similar if the surface roughness is close to each other.

\subsection{INSULATION STRENGTH}

Ten flashover voltages in a consecutive experiment in Figure 2 are averaged for each specimen and shown as a function of the roughness in Figures $3 a$ and $3 b$, respectively, for $\mathrm{SiO}_{2}$ and PMMA. The error bars in these figures indicate the minimum, usually the first, and the maximum, the last, flashover voltages of the ten shots. The

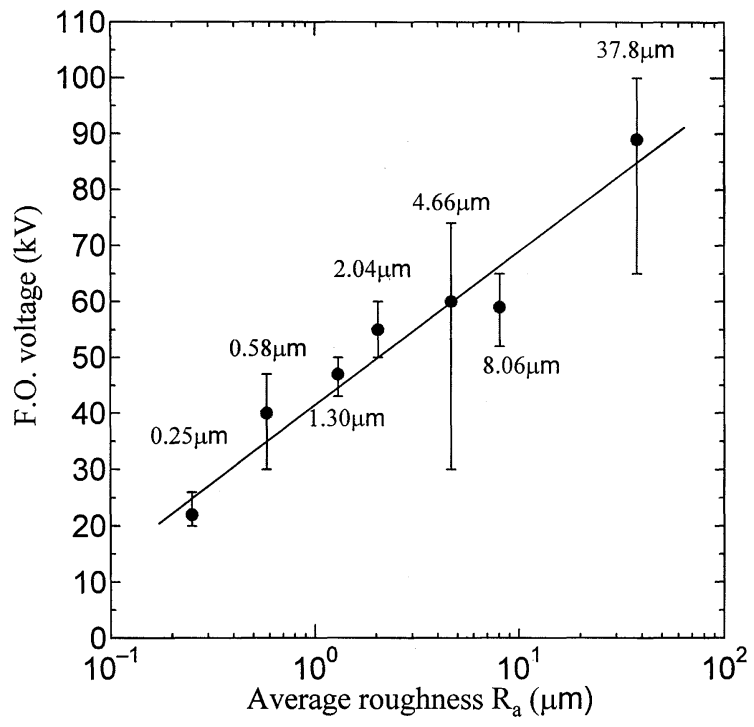

(a)

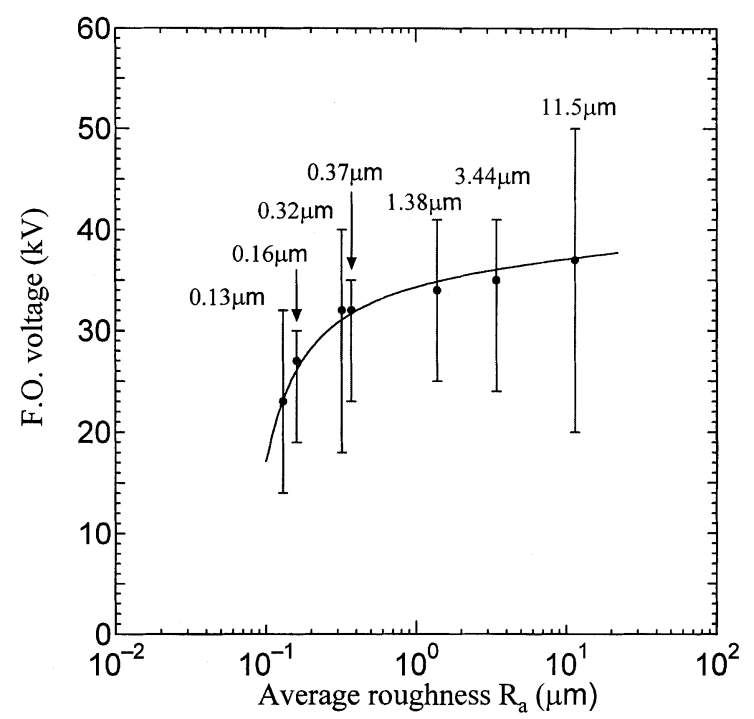

(b)

Figure 4. Flashover characteristics of PTFE and $\mathrm{Al}_{2} \mathrm{O}_{3}$. a, PTFE; b, $\mathrm{Al}_{2} \mathrm{O}_{3}$.

increase in the average flashover voltage is distinct when the surface roughness is larger than about $1 \mu \mathrm{m}$ for both materials.

Figures $4 \mathrm{a}$ and $4 \mathrm{~b}$ show the corresponding results for PTFE and $\mathrm{Al}_{2} \mathrm{O}_{3}$. For PTFE, the average flashover voltage increases almost linearly, on the semi-logarithmic scale, with the roughness ranging from 0.25 to $37.8 \mu \mathrm{m}$. The flashover voltage of $\mathrm{Al}_{2} \mathrm{O}_{3}$ increases with increasing roughness from 0.13 up to $0.32 \mu \mathrm{m}$, but it becomes saturated for larger roughness.

One of the important results in the above experiments is that the first flashover voltage for a series of voltage applications increases with the surface roughness. This result is shown in Figure 5 for the four materials. Although 


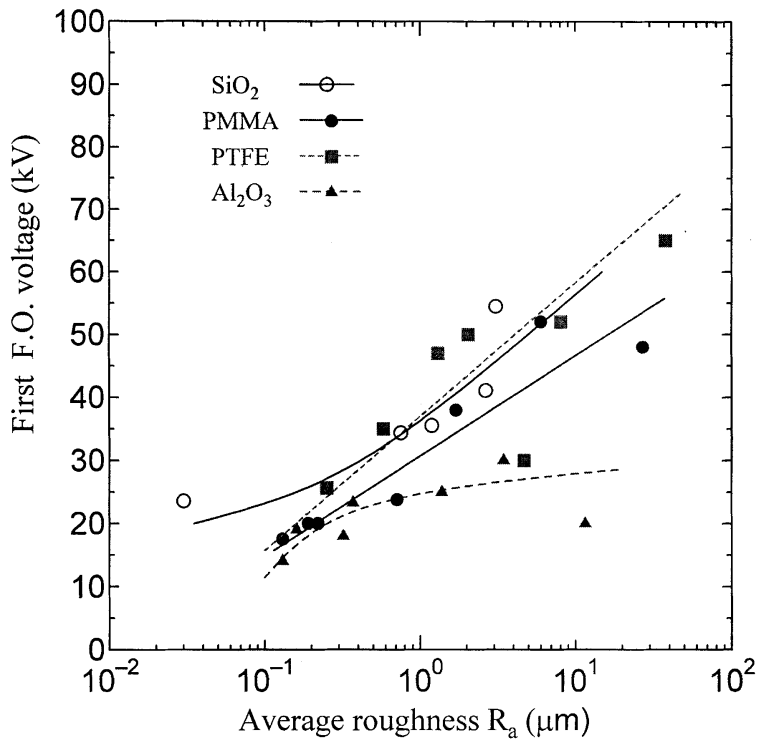

Figure 5. The first flashover voltage as a function of $R_{a}$.

the first flashover voltage shows saturation for $\mathrm{Al}_{2} \mathrm{O}_{3}$, it increases almost linearly on the semi-logarithmic scale with the roughness for $\mathrm{SiO}_{2}$, PMMA and PTFE. This fact indicates that, by roughening the insulator surface, we obtain higher insulation strength before conditioning with sparks.

\section{SURFACE CHARGING}

\section{1 $\mathrm{SiO}_{2}$ INSULATOR}

Figure 6a shows an example of simultaneous measurement of an applied voltage $V_{a p}$ and a probe signal $E_{T J}$ when a $\mathrm{SiO}_{2}$ insulator with a smooth surface is subjected to a ramped voltage.

The geometrical field $E_{g}, V_{a p} / d(d=10 \mathrm{~mm})$, is plotted on the left ordinate. When the charging starts, the surface charge component $E_{s}$ is superimposed on the geometrical field. The charging starts suddenly at $18 \mathrm{kV}$ and after inception the charge component increases almost linearly with the applied voltage. The applied voltage was turned off at $30 \mathrm{kV}$ in this case. Even after the voltage is removed, the electric field due to the residual charge on the surface remains. As already mentioned, the residual charge is neutralized by a silent discharge after the voltage removal.

Increasing the roughness raises the inception voltage and decreases the surface charge component as can be seen in Figure 6b. The surface charge component eventually disappears for larger roughness as shown in Figure 6c.

\subsection{PMMA AND $\mathrm{AL}_{2} \mathrm{O}_{3}$ INSULATORS}

PMMA and $\mathrm{Al}_{2} \mathrm{O}_{3}$ insulators show similar charging process except that the charging of these insulators starts at a much lower applied voltage. It is $6-7 \mathrm{kV}$ for PMMA and 6-10 kV for $\mathrm{Al}_{2} \mathrm{O}_{3}$. Furthermore, in the $\mathrm{Al}_{2} \mathrm{O}_{3}$ insu-

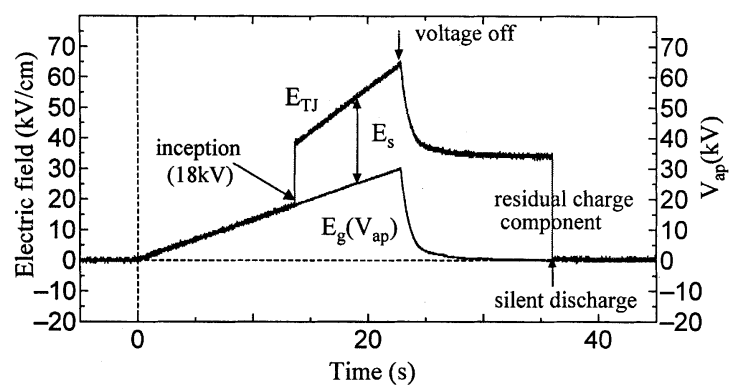

(a) $R_{a}=0.03 \mu \mathrm{m}$

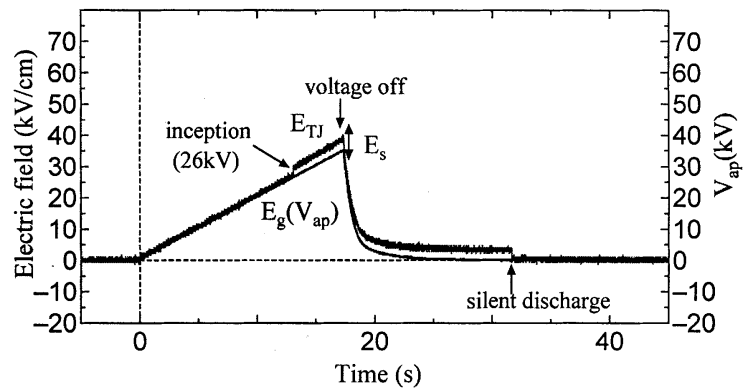

(b) $\mathrm{R}_{\mathrm{a}}=1.19 \mu \mathrm{m}$

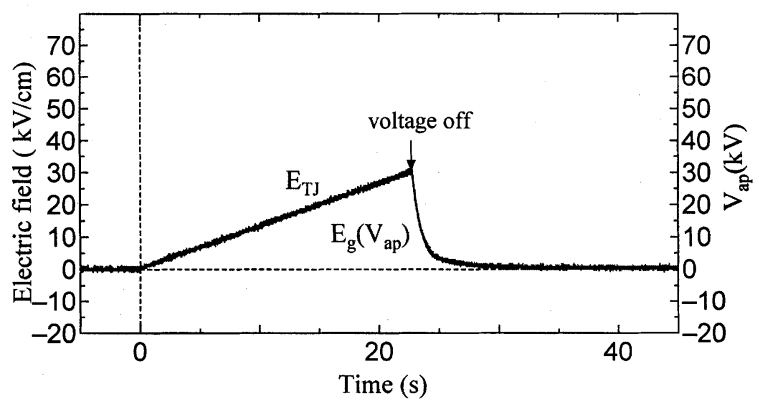

(c) $\mathrm{R}_{\mathrm{a}}=3.07 \mu \mathrm{m}$
Figure 6. Change in probe signal with surface roughness $\left(\mathrm{SiO}_{2}\right)$.

lator case, the surface charge component increases by steps for comparatively rough surfaces. Figures $7 \mathrm{a}, 7 \mathrm{~b}$ and $7 \mathrm{c}$ demonstrate the change in the probe signal with three classes of surface roughness.

\subsection{PTFE INSULATOR}

PTFE insulators scarcely acquire the surface charge under an applied voltage below $40 \mathrm{kV}$ irrespective of surface roughness. We observed the charging only once for the smoothest specimen. However, even these PTFE insulators acquire surface charge, irrespective of surface roughness, if the applied voltage becomes close to the flashover voltage. The charging in such cases is demonstrated in Figure 8.

A peculiar nature of PTFE insulators has been pointed out by Chalmers et al. [8], that the polarity of charge changes from negative to positive as the applied voltage increases. They attributed this phenomenon to the influ- 


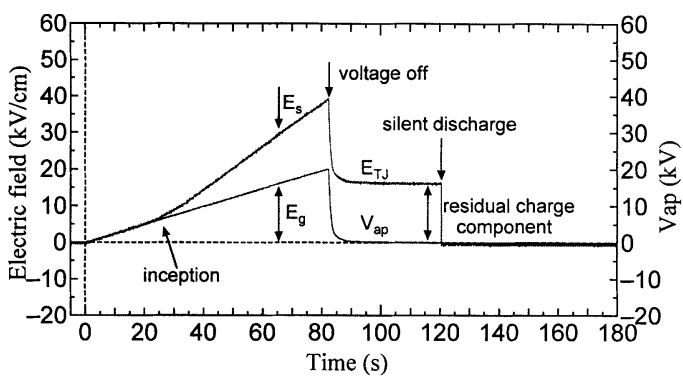

(a) $\mathrm{R}_{\mathrm{a}}=0.13 \mu \mathrm{m}$

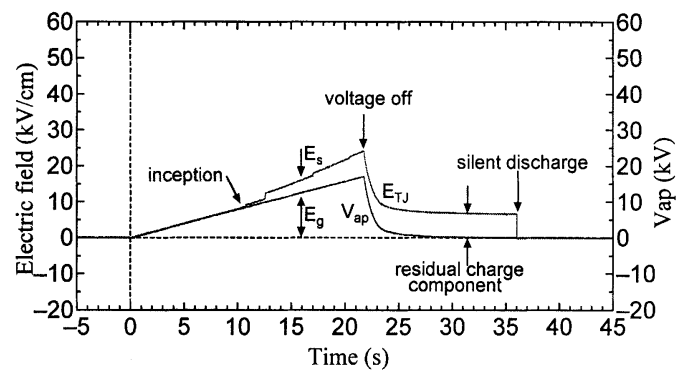

(b) $\mathrm{R}_{\mathrm{a}}=0.32 \mu \mathrm{m}$

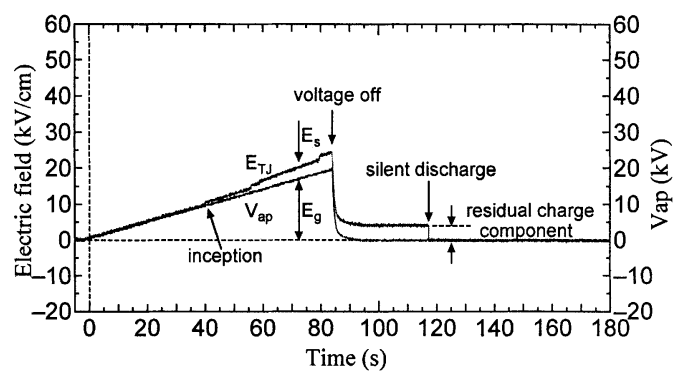

(c) $\mathrm{R}_{\mathrm{a}}=1.38 \mu \mathrm{m}$

Figure 7. Change in probe signal with surface roughness $\left(\mathrm{Al}_{2} \mathrm{O}_{3}\right)$.

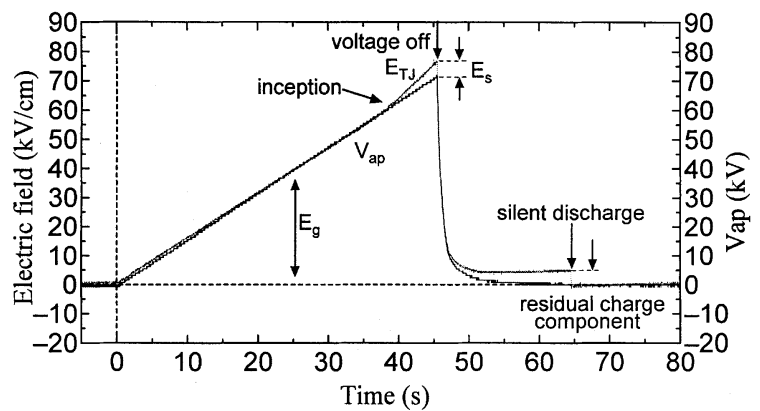

Figure 8. Charging of a PTFE insulator with rough surface.

ence of tribo-electricity. We checked the potential of a PTFE insulator set on a grounded electrode by using a surface potential meter. We have found that the surface potential is negative and decreases to $-3 \mathrm{kV}$. Such potential could be formed by only a touch of a finger covered with a polymer or a paper. In the case of the other materials used in this study, the surface potential was always positive.

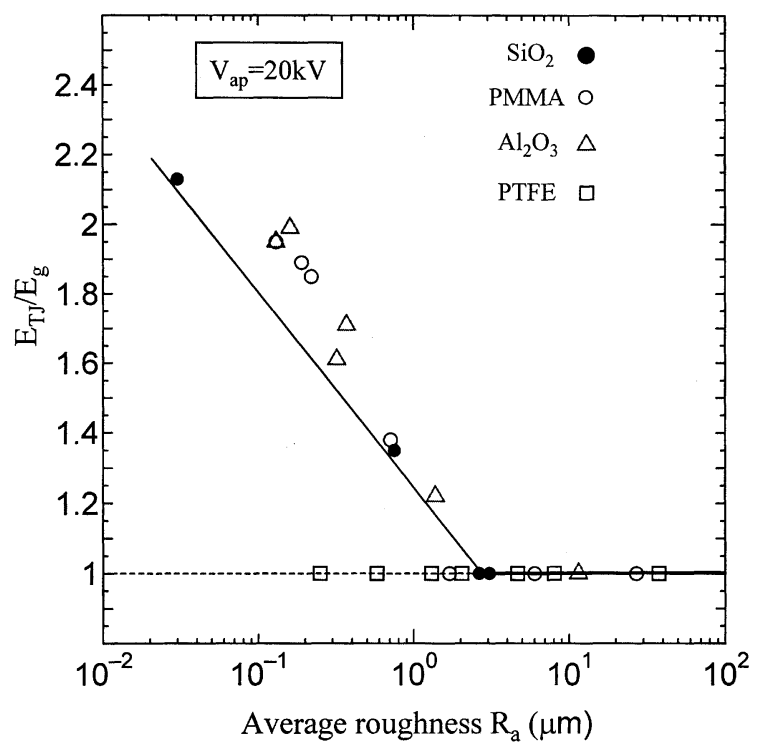

Figure 9. Magnitude of acquired charge at $20 \mathrm{kV}$.

As the measured surface potential of PTFE is low compared to the applied voltage, we have not taken it into consideration in this study. However, we need a further study on the influence of frictional charge as it might affect the charging onset voltage level that depends on the material.

\subsection{DEPENDENCE OF $E_{T J} / E_{g}$ ON ROUGHNESS}

We summarize the characteristics of charging in terms of the surface roughness. Figure 9 shows the normalized electric field strength $\left(E_{T J} / E_{g}\right)$, which demonstrates the magnitude of surface charge, as a function of surface roughness when the applied voltage is $20 \mathrm{kV}$. It can be seen that the surface roughness decisively affects the charging of $\mathrm{SiO}_{2}, \mathrm{PMMA}$ and $\mathrm{Al}_{2} \mathrm{O}_{3}$ insulators.

The surface charge magnitude of these insulators decreases linearly with roughness on a semi-logarithmic scale, and becomes zero for $R_{a}$ larger than 1 or $2 \mu \mathrm{m}$. It needs a higher voltage to cause charging on these insulator surfaces. Furthermore, the difference in the magnitude is small among these three materials.

\subsection{FLASHOVER AND CHARGING CHARACTERISTICS}

Although the mechanism that can explain the process from surface charging to flashover is not clear at the moment [9], the charging characteristics of $\mathrm{SiO}_{2}$ and PMMA suggest that the flashover becomes hard to take place when the surface roughness $R_{a}$ is larger than 1 or $2 \mu \mathrm{m}$. This is in good agreement with the results shown in Figures 3a and $3 \mathrm{~b}$, where the flashover voltages of $\mathrm{SiO}_{2}$ and PMMA show, respectively, a distinct increase at nearly the same roughness. 
The spacer made of $\mathrm{Al}_{2} \mathrm{O}_{3}$ shows almost the same charging characteristic, however, its flashover characteristic is different from those of $\mathrm{SiO}_{2}$ and PMMA. That is, both the first and the average flashover voltages saturate with increasing roughness. The $\mathrm{Al}_{2} \mathrm{O}_{3}$ has an extremely high relative permittivity as indicated in Table 1 . Thus, it is possible that with imperfect contact between the insulator and the cathode, the electric field strength at the cathode triple junction is so high as to cause discharge relying on a mechanism independent of the charge magnitude. We will conduct a further experimental study on this point by changing the contact condition.

\section{DISCUSSION}

According to our previous studies, cylindrical insulators subjected to high voltage in vacuum acquire positive charge on the surface that results in enhancement of the electric field at the cathode surface near the triple junction [4,7]. The mechanism of charging has been well established by Boersh et al. [1].

Roughening the insulator surface inevitably modifies the potential of the triple junction. That is, the circumference corners at both ends of a cylindrical insulator are roughened too, which would result in imperfect contact at the cathode junction. Thus, one may consider that roughening the insulator would increase the field emission of electrons and facilitate the charging. However, the experimental result shows the opposite characteristic as in Figure 9.

In order to investigate the influence of surface roughness on charging, we calculated trajectories of secondary electrons and analyzed their hopping height from the insulator surface. The insulator had the same diameter and height as used in the experiment. The injection point of an initial electron was $10 \mu \mathrm{m}$ away from the junction on the cathode. When releasing an initial electron from the cathode, we assumed that the insulator surface had already been charged at an equilibrium state, in which the charge distribution was such that the secondary electron yield was unity all over the surface [1]. The charge density which depends on the insulator material and the voltage level being applied [10] in turn influences on the hopping height. A Monte Carlo technique [10] was employed for the trajectory simulation.

Figure 10 shows an example of trajectories calculated for PMMA specimen having an ideal smooth surface. The applied voltage is fixed at $20 \mathrm{kV}$ and the secondary electron energy $A_{s}$ is assumed to be $13 \mathrm{eV}$. We have chosen a comparatively high $A_{s}$ to estimate a larger hopping height which would meet the simulation purpose. The average hopping height $h_{e}$ of the secondary electrons is approximately $0.3 \mu \mathrm{m}$. Note that this height is considerably smaller than the insulator roughness when charging no longer occurs $\left(R_{a}=1-2 \mu \mathrm{m}\right.$; See Figure 9$)$. Thus, in the case of an insulator with a roughness larger than $h_{e}$, the projections on the insulator surface act as barriers for sec-

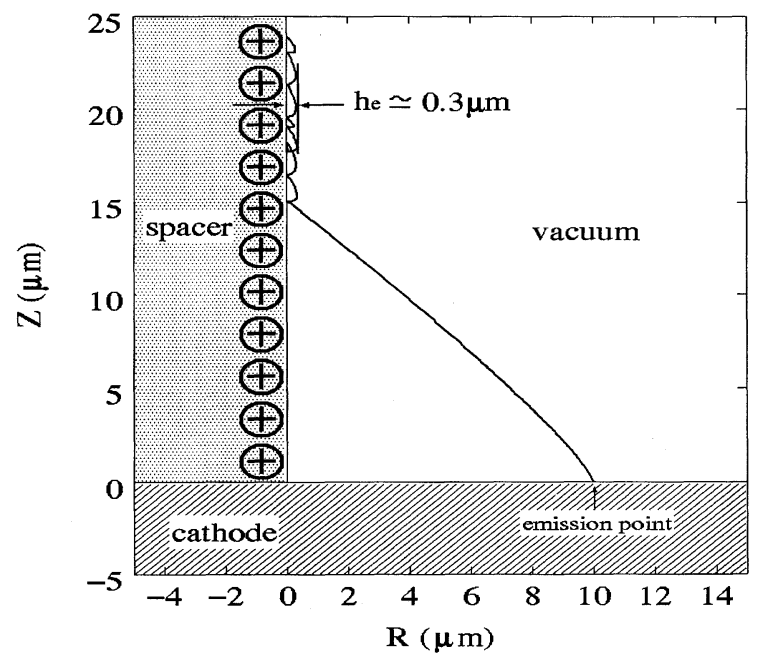

Figure 10. Simulated electron trajectory for PMMA at $V_{a p}=20 \mathrm{kV}$.

ondary electrons by interrupting their movement. This means that it is hard with the projections to reach the equilibrium state that is expected for a smooth insulator. We believe that this is the main reason why the surface roughness decisively affects charging.

\section{CONCLUSION}

$T$ HE surface roughness of an insulating spacer decisively affects both surface charging and flashover voltage for most of the materials examined in this study. Increasing the roughness prevents surface charging and increases the flashover voltage. For $\mathrm{SiO}_{2}$, PMMA and $\mathrm{Al}_{2} \mathrm{O}_{3}$, roughness larger than an average of 1 or $2 \mu \mathrm{m}$ is necessary to prevent charging (at $20 \mathrm{kV}$; specimen length $10 \mathrm{~mm}$ ). According to the simulation results, surface protrusions act as barriers against the movement of secondary electrons in the SEEA process.

The first flashover is extremely significant in practical vacuum insulation systems, because the high energy at the flashover is likely to damage the insulator and/or the surrounding metallic parts. Roughening the insulator surface is clearly effective to increase the first flashover voltage for insulator materials such as $\mathrm{SiO}_{2}$, PMMA and PTFE. We believe that the quantitative data of this study present useful information for designing an insulating spacer for high voltage vacuum devices.

\section{ACKNOWLEDGMENT}

We thank Mr. Shioiri, of Toshiba Co., for his support in measuring the roughness of the specimens and also for supplying alumina specimens for this study. We thank Mr. T. Harasawa who was involved in some of the experiments for his Bachelor thesis at Kyoto University.

\section{REFERENCES}

[1] H. Boersch, H. Harmish, and W. Ehrlich, "Surface Discharge Across Insulators in Vacuum", Z. Angew Phys., Vol. 15, pp. 518-525, 1963. 
[2] H. Kawai, H. Matsuura, S. Michizono, Y. Saito, and A. Inagaki, "Effect of Surface Processing on the Secondary Electron Yield of Alumina Ceramic", Vacuum, Vol. 36, pp. 257-259, 1993. (In Japanese)

[3] R. G. Bommakanti and T. S. Sudarshan, "Influence of Mechanical Grinding and Polishing Operations of Brittle Polycrystalline on the Pulsed Surface Flashover Performance", J. Appl. Phys., Vol. 67, pp. 6991-6007, 1990.

[4] O. Yamamoto, T. Takuma, Y. Kakehashi, S. Ikoma, and T. Shioiri, "Delay Characteristics of Surface Charging on a Cylindrical Insulator in Vacuum", IEEE Trans. DEI, Vol. 7, pp. $812-817,2000$

[5] H. Seiler, "Secondary Electron Emission in the Scanning Electron Microscopy", J. Appl. Phys., Vol. 54, pp. 1-18, 1983.

[6] E. A. Burke, "Secondary Electron Emission from Polymers", IEEE Trans. on Nuclear Science, Vol. 27, pp. 1760-1764, 1980.

[7] O. Yamamoto, T. Takuma, and T. Tanabe, "Real-Time Observation of Surface Charging on a Cylindrical Insulator in Vacuum", IEEE Trans. DEI, Vol. 5, pp. 961-965, 1998.

[8] I. D. Chalmers, J. H. Lei, B. Yang, and W. H. Siew, "Surface Charging and Flashover on Insulators in Vacuum", IEEE Trans. DEI, Vol. 2, pp. 225-230, 1995.

[9] H. C. Miller, "Flashover of Insulators in Vacuum", IEEE Trans. EI, Vol. 28, pp. 512-527, 1993.

[10] O. Yamamoto, T. Hara, I. Nakanishi, and M. Hayashi, "Monte Carlo Simulation of Surface Charge on Angled Insulators in Vacuum", IEEE Trans. EI, Vol. 28, pp. 706-712, 1993.

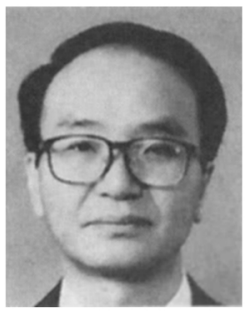

Osamu Yamamoto (M'02) was born on 22 February, 1948 in Japan. He received the B.S. degree in Physics from Ritsumeikan University in 1970 and the D.Eng. in electrical engineering from Kyoto University in 1982. He joined Kyoto University in 1971 as a research associate. He has been engaged in studies of $\mathrm{HV}$ engineering especially on insulation characteristics and discharge mechanisms in gases including pressurized gas mixtures, surface flashover characteristics and mechanisms in vacuum. $\mathrm{He}$ is also interested in the gas separation and recovery technique from insulation gas mixtures and also investigations on the surge response of power transmission tower.

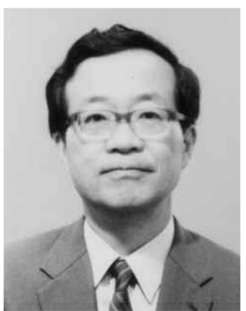

Tadasu Takuma (M'91) was born on 13 September 1938 in Japan. He received the B.S., M.S., and Ph.D. degrees in electrical engineering from Tokyo University in 1961, 1963 and 1966, respectively. He joined Central Research Institute of Electric Power Industry (CRIEPI) in 1967, where he was engaged in the study of $\mathrm{SF}_{6}$ gas insulation, gas discharge, environmental problems of transmission lines, numerical field calculation, and new energy problems. He was Professor in the Department of Electrical Engineering, Kyoto University, from 1995 to 2002. He has been in CRIEPI since April, 2002. He received the Maxwell Premium from the Institute of Electrical Engineers, Great Britain, in 1974, and twice the Book Prize on his books entitled "Numerical Calculation Methods of Electric Fields" (in Japanese) and "High Voltage-High Current Engineering" (College Textbook, in Japanese), respectively, in 1981 and 1991, from IEE Japan.

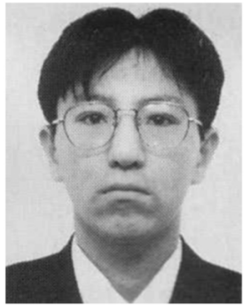

Satoru Nagata was born on 4 July 1977 in Japan. He received the B.S. and M.S. degrees in electrical engineering from Kyoto University in 2000 and 2002, respectively. He is currently working for Chubu Electric Power Company.

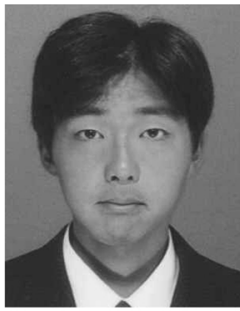

Masaki Fukuda was born on 11 March 1979 in Japan. He received the B.S. degree in electrical engineering from Kyoto University in 2001. He is currently engaged in research on the surface discharge phenomena in vacuum for his M.S. thesis study.

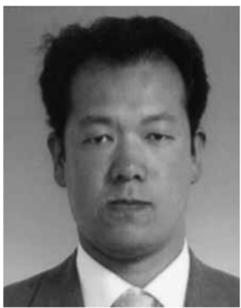

Toshio Sonoda was born on 15 July 1965 in Japan. He graduated from Seta Technical High School, Shiga Prefecture and joined The Kansai Electric Power Co. Inc. (KEPCO), Osaka, Japan in 1984. He has been engaged in research on power systems at General R\&D Center in KEPCO.

This paper is based on a presentation given at the 20th ISDE IV Conference, Tours, France, 1-5 July 2002. 